\title{
ENERGY-EFFICIENT NEW COMMERCIAL BUILDINGS IN THE NORTHWEST REGION: A COMPILATION OF MEASURED DATA
}

\author{
Mary Ann Piette and Denise Flora \\ Buildings Energy Data Group \\ Lawrence Berkeley Laboratory \\ University of California \\ Berkeley, CA 94720 \\ and \\ Scott Crowder \\ Battelle Pacific Northwest Laboratories \\ Richland, WA 99352
}

May 1985

\begin{abstract}
The work described in this paper was funded by the Bonneville Power Administration and the Assistant Secretary for Conservation and Renewable Energy, Office of Building Energy Research and Development, Building Systems Division of the U.S. Department of Energy under Contract No. DE-AC03-76SF00098.
\end{abstract}




\begin{abstract}
We have collected and analyzed data for 36 new commercial buildings designed to be energy-efficient in the Northwest. Eighteen buildings are offices; the remainder are mostly retail buildings, and schools. The data were collected and analyzed to evaluate the building energy standards adopted by the Northwest Power Planning Council in the Northwest Conservation and Electric Power Plan. Almost half of the buildings are operating at energy levels under the Council's estimates for new efficient commercial buildings. There is, however, a large range of energy intensities. The average office building consumes $54 \mathrm{kBtu} / \mathrm{ft}^{2}-\mathrm{yr}$ (in site energy units), while the average small office uses only $43 \mathrm{kBtu} / \mathrm{ft}^{2}-\mathrm{yr}$. Energy consumption for the eight retail buildings ranges from $47 \mathrm{kBtu} / \mathrm{ft}^{2}$-yr to $134 \mathrm{kBtu} / \mathrm{ft}^{2}$-yr.
\end{abstract}

KEYWORDS: Energy Conservation, Commercial Buildings, Office Buildings, Monitoring, Energy Efficiency. 



\section{INTRODUCTION}

The Northwest Power Planning Council and the Bonneville Power Administration (BPA) are adopting energy-efficiency standards for new, electrically heated commercial buildings. Although energy-efficiency is an important design criterion for many new commercial buildings, energy performance and cost-effectiveness of the energy conservation strategies have not been thoroughly evaluated for actual buildings. Measured data on commercial building energy performance relative to the energy standards are important for evaluating technical and policy issues related to energy conservation in buildings.

In developing the Northwest Conservation and Electric Power Plan, the Northwest Power Planning Council assessed the potential for electrical energy conservation in new commercial buildings. They developed estimates of annual energy use for ten categories of new, energyefficient commercial buildings [1]. These estimates are used in the Council's forecasting models to determine future demand for electricity. The adopted energy standards for commercial buildings, called the Model Conservation Standards (MCS) are a modified version of the model energy code of the American Society of Heating, Refrigeration, and Air Conditioning Engineers (ASHRAE), ASHRAE 90-80 [2].

To lend additional support to the estimates for new energy-efficient buildings, we compiled and analyzed measured data on the performance and cost-effectiveness of thirty-six, new, occupied commercial buildings designed to be efficient in the Northwest. The data are stored in Lawrence Berkeley Laboratory's (LBL) "BECA-CN" data base (Buildings Energy Use Compilation and Analysis of Energy Efficient New Commercial Buildings). This regional data base is part of the national BECA-CN data base, one in a series of BECA data bases maintained by LBL (with U.S. Department of Energy funding) for both residential and commercial buildings.

Our goal was to compile data on the actual performance of buildings to assess the estimates developed by the Council. Moreover, we hope to create an information source useful to researchers, and building designers, owners, and operators on how well conservation efforts work in practice. We use the term "energy-efficient" in this paper, but we acknowledge the complexities associated with assessing commercial building energy performance and therefore use the term with caution. The BECA-CN data include three basic types of "efficient" buildings. First, there are buildings designed to be energy efficient that are successfully operating at low energy intensities. Second are the buildings designed to be efficient but operating at high energy intensities, substantially above their design values. Third are those without special energy features, but operating at comparatively low energy levels.

This paper is organized into three main sections. The first section is a discussion of data collection and manipulation procedures. The second contains our analysis of the buildings' energy use and operating characteristics, in which we compare these buildings to the estimates for new 
"efficient" buildings and other benchmarks. In addition, we discuss specific findings from our analysis and limitations of the available data. The final section summarizes our findings and their implications.

\section{METHODOLOGY AND DATA}

\subsection{Data Sources}

From June 1984 through December 1984, we pursued data on nonresidential buildings in the Northwest that were designed to be energy efficient. Sources of data included:

o mailing to 450 Architect/Engineers, utility, and state Department of Energy contacts,

o building energy studies and reports,

- awards programs,

o magazine articles,

o "word of mouth" leads.

Over 150 individual new commercial buildings were identified and contacted. Only a small fraction of these leads were included in the data base. Many of the leads were rejected because the buildings were too new to have a full year of operating data that we required, had no notable energy-efficient features, or were not cooperative in supplying data. The data collected are not intended to be statistically representative of new construction; there are many "efficient" buildings in the Northwest not included in the compilation.

\subsection{Building Type}

Retail buildings were a major focus of this study since little information is available for this fast growing sector. In addition, we sought data for offices, schools, and other nonresidential buildings. Data have been more readily available for offices than any other type of building.

In general, energy data for new retail buildings are scarce. Within the retail sector, we emphasized the collection of shopping center energy data since most new, U.S. retail construction, as reported in trade journals, will be in shopping centers $[3]$. The paperwork required to obtain information for all of the stores in one shopping center is generally prohibitive. Metering arrangements in malls also complicate data collection. In some cases the central mall administration contracts with the utilities directly, submetering electricity to the shops or simply charging a fixed fee included in the rent. In other cases the shops are billed directly by the utility.

\subsection{Data Collection and Analysis}

Data sought for each building include:

o energy - usage, peak demand, and costs for at least one year; predicted energy usage (and description of prediction method), 
o building description - location, completion date, gross and conditioned floor area, building type,

$\circ \quad$ energy-saving features - lighting, daylighting, Heating, Ventilation, and Air Conditioning (HVAC) system(s), controls, building envelope,

operating conditions - hours, occupancy, process loads, lighting levels, temperature settings, ventilation rates,

- economics - total construction cost, maintenance costs, incremental cost of energy-saving features.

For a building to be included in the BECA-CN data base we need to know at a minimum: size, type, location, year built, annual energy consumption, and information about the operating characteristics and features. The DATATRIEVE data base management system is used for storing and manipulating these data. Appendix A contains the detailed data tables summarizing pertinent information for each of the 36 buildings. The data were analyzed using techniques developed for the national data base compilation. "A Summary Report of BECA-CN: Buildings Energy-Use Compilation and Analysis of Energy-Efficient New Commercial Buildings" discusses these techniques [4].

The operating data are presented for the most recent year for which energy data are available (see Appendix A). Gross floor area is used to area-normalize the data, except for three buildings for which we only have conditioned floor area. Gross floor area may include enclosed parking areas if we could not separate parking area (see the "Energy Intensity vs. Building Size" section for further discussion). If parking areas are included a note appears in the comment section of the data tables. To account for the differences between the conditioned and gross floor area the data tables contain the ratio between these two values when both were reported.

\section{RESULTS}

We have analyzed data for thirty-six new buildings. The sample includes both very low energy buildings, and buildings that operate above the stock average or Council's estimates.

\subsection{Distribution of Energy Consumption}

Figure 1 shows the range of energy intensities among the thirty-six Northwest BECA-CN buildings, grouped by energy intensity and building type. The first bar of each cluster represents the office buildings (including two branch banks). The second bar, with the five shading patterns, includes the other five building types for which we were able to collect data. The range shows the low-energy buildings at the left end, and the buildings built with some special features but containing process loads (such as computers), or operating under more intensive or inefficient conditions, at the right end. Half (ten) of the office buildings fall into the second bin; they operate between 41 and $60 \mathrm{kBtu} / \mathrm{ft}^{2}-\mathrm{yr}$. 


\section{Energy Intensity \\ for Northwest BECA-CN}

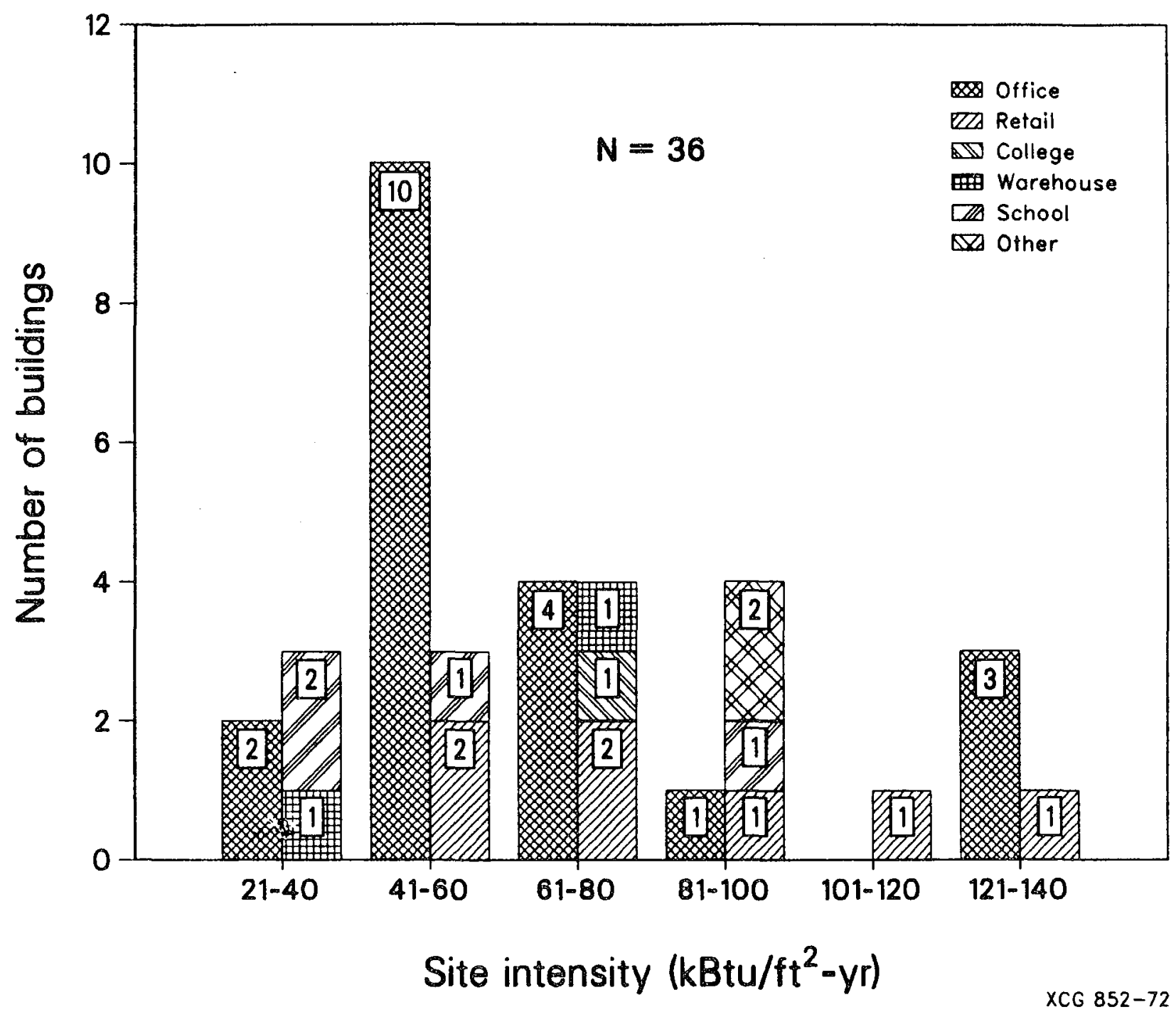

Figure 1. Distribution of energy intensities for Northwest BECA-CN buildings. The first bar contains both large and small offices (including two branch banks); the second, all other building types. The distribution for offices strongly peaks in the 41-60 kBtu $/ \mathrm{ft}^{2}-\mathrm{yr}$ bin. The next largest sample, retail buildings, are well spread across the range of intensities. 


\subsection{Energy Performance: Comparison to Standards and Stock}

The comparisons in this section address the questions, "what is an energy-efficient building?", and "efficient compared to what?" A brief analysis of each building type is included (see Table 1). We compare the energy performance of the BECA-CN sample with:

- simulation results of the proposed ASHRAE 90E standard for Seattle [5],

- estimates of energy use for new energy-efficient all-electric buildings under the regional energy standards [1],

o estimates of the average, new, all-electric commercial stock in the Northwest [1].

\begin{tabular}{|c|c|c|c|c|c|c|c|c|c|}
\hline \multirow{3}{*}{$\begin{array}{c}\text { Building } \\
\text { Type }\end{array}$} & \multicolumn{4}{|c|}{ All Electric and Mixed Fuels (kBtu/ft ${ }^{2}-\mathrm{yr}$ ) } & \multicolumn{5}{|c|}{ All Electric Only $\left(\mathrm{kWh} / \mathrm{ft}^{2}-\mathrm{yr}\right)$} \\
\hline & & All B & $\mathrm{CN}$ & ASHRAE & & ectric & $\mathrm{CA}-\mathrm{CN}$ & MCS & All Elec. \\
\hline & $\mathbf{N}$ & Avg. & Range & $90 \mathrm{E}$ & $\mathrm{N}$ & Avg. & Range & Esimates & New Stock \\
\hline Large Office & 11 & 70 & $44-129$ & $43-49$ & 8 & 22 & $13-38$ & 18 & 30 \\
\hline Small Office & 9 & 57 & $35-135$ & $39-63$ & 6 & 19 & $10-39$ & 18 & 30 \\
\hline $\begin{array}{l}\text { Small Office } \\
\text { w/out Bank }\end{array}$ & 7 & 43 & $35-50$ & & 4 & 12 & $10-14$ & 18 & 30 \\
\hline All Office & 20 & 54 & $35-135$ & & 14 & 20 & $10-39$ & 18 & 30 \\
\hline All Retail & 7 & 82 & $47-134$ & & 7 & 24 & $14-39$ & 18 & 30 \\
\hline $\begin{array}{c}\text { Retail w/out } \\
\text { Mall }\end{array}$ & 6 & 73 & $47-105$ & $57-68$ & 6 & 22 & $14-29$ & 18 & 30 \\
\hline College & 1 & 74 & & & 1 & 22 & & 22 & 25 \\
\hline Schools & 4 & 50 & $32-91$ & $63-82$ & 2 & 10 & $9-10$ & 14 & 19 \\
\hline $\begin{array}{c}\text { Warehouse } \\
\text { (both are } \\
\text { part offices) }\end{array}$ & 2 & 47 & $32-62$ & $69-81$ & 1 & 18 & & 10 & 16 \\
\hline $\begin{array}{l}\text { Other bldgs } \\
\text { (research \& } \\
\text { assembly) }\end{array}$ & 2 & 97 & $95-99$ & & 1 & 28 & & 11 & 17 \\
\hline
\end{tabular}

* Regional Conservation and Electric Power Plan, Draft, January 26, 1983, p. k35 
We have analyzed the total Northwest BECA-CN sample and the subset of the all-electric buildings independently since the MCS are for electrically heated buildings. Twenty-six of these thirty-six buildings are all-electric. For all building types except the all-electric warehouse and the "other" type building, the least energy intensive all-electric BECA-CN buildings use less energy than the estimates for new efficient buildings under the regional standards. For most building types, the average all-electric BECA-CN building is also close to the estimates for the the regional standards, and significantly below the average all-electric new stock. In general, buildings can meet the estimated energy intensities for new construction under the regional standard, but it is often difficult to say why one building does, and another does not.

The proposed ASHRAE standard 90E ranges are included because they provide useful comparison values for buildings with mixed fuels, and the earlier, less stringent version of the standard, ASHRAE 90-80, was used in the derivation of the adopted regional standards. The ASHRAE 90E values span the lower range of the BECA-CN data for each building type. They are derived from simulations with the DOE 2.1 computer program for prototype commercial buildings with different HVAC system configurations using Seattle weather, and approximate how a building would perform under the proposed standard [5].

The ASHRAE values do not include energy used for exterior lighting, and assume only minimal process loads $\left(0.5\right.$ to $\left.1.0 \mathrm{~W} / \mathrm{ft}^{2}\right)$. This exclusion should be kept in mind when making comparisons because we cannot separately account for energy used by miscellaneous loads, such as exterior lighting or process loads, in BECA-CN buildings. In the future we hope to correct for the energy consumption of these miscellaneous systems. This correction requires data measured by end-use (e.g. specific lighting or heating system consumption).

Almost half of the BECA-CN buildings operate below the regional standards estimates. Figure 2 compares building performance as a percentage of the standard. For each building type the BECA-CN data range from about half to about twice the standard. Average new all-electric stock (see Table 1) and average existing stock data are also included for reference [1]. These stock estimates are based on samples of commercial buildings data collected by the Council, which include regional surveys and utility program results. Eight BECA-CN buildings are actually above the average stock. Again, we distinguish between mixed fuel and all-electric buildings because the regional standards are for all-electric buildings. 


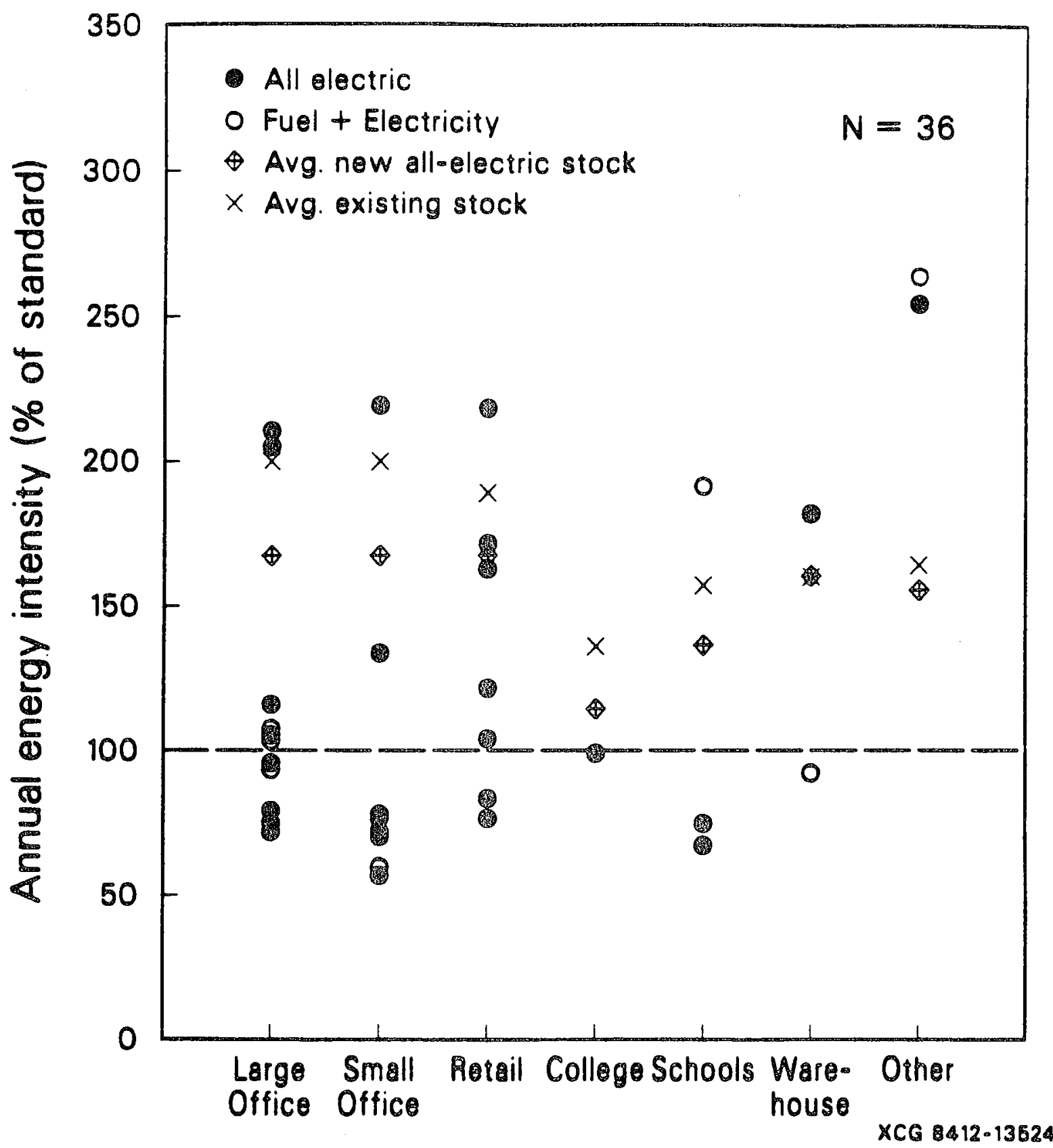

Figure 2. Annual energy intensity of Northwest BECA-CN as a percentage of the estimates for new efficient buildings under the regional standards. Average new all-electric stock estimates and average overall stock estimates are included for reference. Almost half of the buildings in the BECA-CN sample are operating below the standard estimates for each building type. The small offices are furthest below. For each type, however, they range to about twice the standard. Eight BECACN buildings are actually above the average stock. The worst energy performance appears to be for the two buildings categorized as "other". These are both energy-intensive building types; one is a community center, the other a research building. The code value for "other" is only $11 \mathrm{kWh} / \mathrm{ft}^{2}-\mathrm{yr}$, the lowest of all the building types, not a good comparison for these two buildings. 
We summarize the data for each building type below.

Offices. The data for offices in Table 1 are organized into four rows because of biases built into each categorization. The small offices (offices with less than 50,000 square feet) appear to use less energy than the other building types; the maximum intensity of the seven small offices is a low $50 \mathrm{kBtu} / \mathrm{ft}^{2}$-yr. In contrast, both branch banks have high energy intensities. They were included in the data base because they utilize solar space heat and hot water systems. These systems are not fully operational because of high maintenance costs. Solar systems are working well elsewhere, however. The most efficient office building in the data base is a small office equipped with active solar space heat and domestic hot water. Ironically, the owner of this office expressed his disappointment in the system, which was designed to supply a greater percentage of the space heat than it was supplying. He is probably unaware of his building's energy performance relative to other small offices. It is not clear why the BECA-CN banks have higher intensities. They do not have abnormally high computer loads--a common explanation--and the operating hours are not drastically different.

Retail. In Table 1 we show two rows of retail data; a large shopping mall is not included in the second row of data because we lack confidence in the floor area used to calculate the energy intensity. We had difficulty reconciling the energy data with the floor area that the meter served because we received differing floor area reports from the building contacts. This mall is further discussed below.

Two of the seven retail buildings had lower energy intensities than the standard. All but one of these retail buildings were department stores. The retail building with the lowest energy use may be efficient because of very low lighting loads $\left(1.1 \mathrm{~W} / \mathrm{ft}^{2}\right)$. As with other low energy buildings, however, it is difficult to attribute the low energy use to particular features.

Schools, Warehouses, and Other. We found a number of low-energy schools. Many of them have innovative features such as "air-flow" windows, extensive daylighting, and earth berming (see Appendix A). The two buildings categorized as "other" are a community center and a research center. It is very difficult to evaluate the energy performance of these "other" buildings because of the variety of building types included in the categorization. The standard for "other" buildings is the second lowest of all building types $\left(11 \mathrm{kWh} / \mathrm{ft}^{2}\right)$. Characterizing building type is also complicated by mixed usages. The two warehouses include significant office space. Without more information about how the energy use is divided between these spaces, they cannot be compared to the estimates for new efficient construction, which are for all-warehouse or all-office spaces. 


\subsection{Specific Findings}

There are a multitude of factors which drive the energy consumption of a particular building. In this section we discuss the results of some of our analyses. Below, we compare the Northwest BECA-CN buildings to each other, to national construction costs data, to national BECA-CN results, and to California BECA-CN buildings. We discuss the energy-efficiency features, construction costs, climate variations, and building size.

Energy Features. We cannot attribute low energy consumption directly to special energy features. We await the availability of actual submetered end-use data to assist in analyzing specific features. However, some overall trends are apparent. Twelve buildings have computerized energy management systems. Many use active and passive solar systems. Seven buildings have some earth berming; eleven have daylighting. Some of the buildings are fairly conventional, but have low energy intensities. Two such are the Federal General Services Administration (GSA) buildings, which have standard HVAC, lighting, and envelope characteristics, and are performing at about average for the sample. The strict temperature requirements for these GSA buildings may explain their low energy use. On the other hand, they may have some large unconditioned spaces included in their floor areas.

Economics. Figure 3 shows energy intensity versus construction cost. One might expect an energy-efficient building to be expensive to build, but there are no obvious correlations. We see that the low energy buildings need not cost more than average. We have seen the same result with the national BECA-CN data.

Obviously, non-energy related factors cause significant variations in building costs. Ideally, to study the cost effectiveness of the energy-saving features we would plot the energy intensity against the incremental cost of the features, but these data are unavailable. The costs have been inflated to first quarter 1984 dollars from the dollars for the year when construction was complete. Average U.S. office construction costs range from about $\$ 55 / \mathrm{ft}^{2}$ to $\$ 85 / \mathrm{ft}^{2}$ (1984 dollars) ${ }^{*}$. For the fifteen offices in Figure 3, seven have construction costs lower than the national average range, three are within the range, and four are above. This analysis does not account for regional price differences; Northwest region construction cost averages are somewhat higher than national averages [7].

As mentioned, this economic analysis is restricted to whole-building costs since it is very difficult to determine the incremental cost of energy-saving features. There are, in addition, other economic factors that should ideally be considered in a thorough analysis. We have not, for example, accounted for investments in energy conservation features that may have taken place

\footnotetext{
This range is derived from 1976 and 1982 data for corporate and general offices of low-, middle-, and high-cost categories representing differences in construction quality and complexity $[6,7 \mid$.
} 


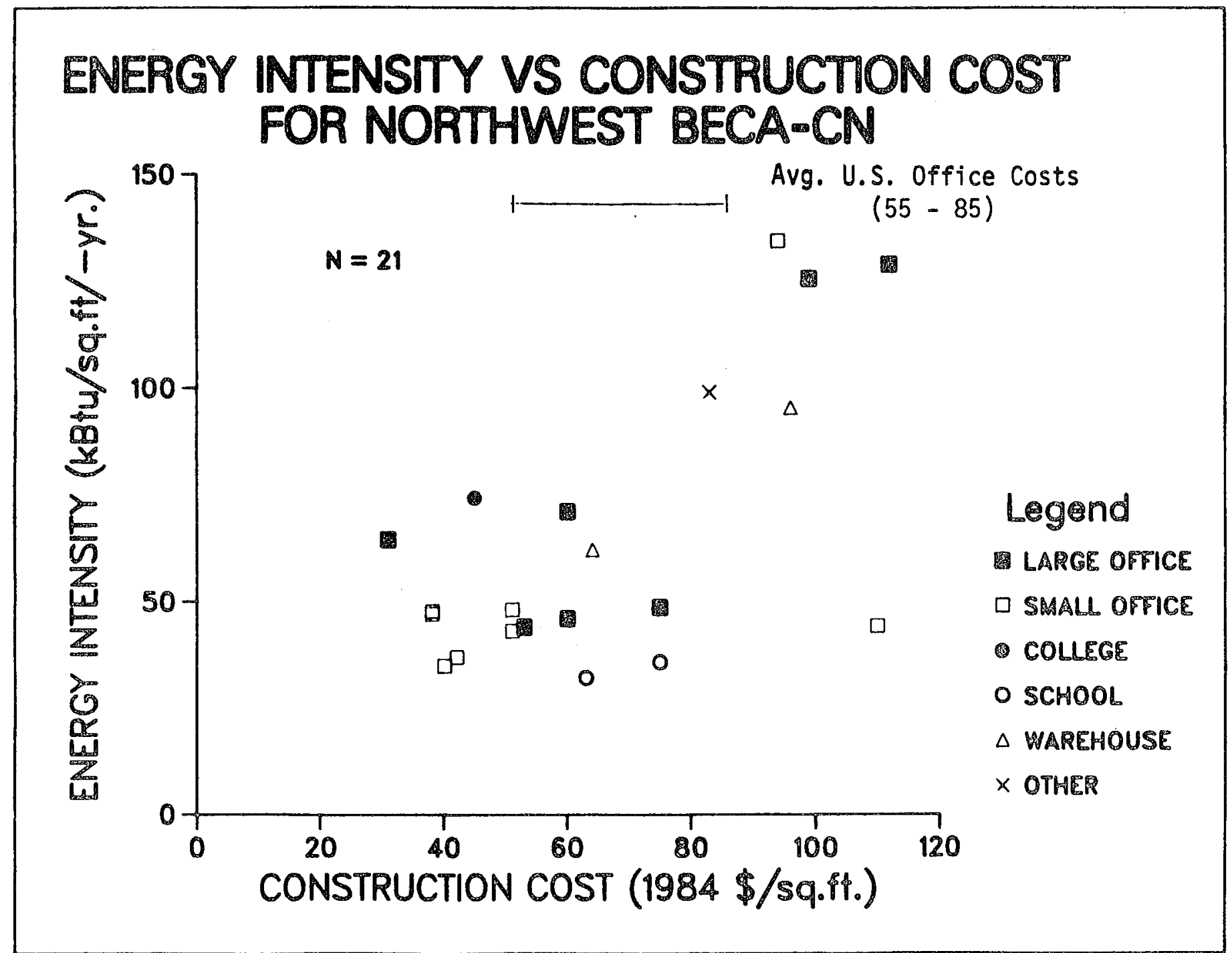

XBL $\quad 857-3131$

Figure 3. Energy intensity versus construction cost for Northwest BECA-CN. Based on this limited subsample of 21 buildings, there is no clear correlation between construction costs per $\mathrm{ft}^{2}$ and energy intensities. It is possible to produce a fairly low energy building over a considerable range of construction costs. The dollars have been adjusted to first quarter 1984 dollars. Average U.S. office costs range from about $\$ 55 / \mathrm{ft}^{2}$ to $\$ 85 / \mathrm{ft}^{2}$. The Northwest building costs are well spread across this range. 
after the first few years of occupancy. It is also difficult to assess and compare any additional maintenance costs associated with energy-saving features. At this time we have only sparse, qualitative information in these areas.

Climate Variations. There is no widely accepted method for taking account of the effect of weather on commercial building energy performance. Our analysis includes some general observations.

We examined the small offices to see how geographical location affects the relationship between winter and summer peak demand (see Figure 4). The buildings further inland in hot areas are summer peaking buildings, while buildings nearer to the coast peak in winter.

We compared the energy intensities of the nine offices east of the Cascade mountain range with the eleven in the west. We thought the eastern buildings might have higher intensities because of more severe winters and hotter summers, but the average intensities are: $59 \mathrm{kBtu} / \mathrm{ft}^{2}$ yr for the eastern offices, and $69 \mathrm{kBtu} / \mathrm{ft}^{2}-\mathrm{yr}$ for the western. This difference seems to be a function of building size and type rather than climate. The average western office had a floor area of $223 \mathrm{kft}^{2}$ while the average eastern office was $46 \mathrm{kft}^{2}$; as discussed above, we found the small offices use less energy per square foot than the large offices.

Northwest versus California Offices. We compared the energy consumption and peak electric demands of the Northwest BECA-CN offices with California BECA-CN offices. Figure 5 shows the energy intensities of these offices. The Northwest offices have both lower peak demands and consume less energy. This is probably a result of a difference in cooling needs. For the twelve Northwest offices with peak data, five buildings peaked between 3 and $4 \mathrm{~W} / \mathrm{ft}^{2}$. Only two of the twelve California offices had summer peaks this low.

Benchmarks have been added to this plot for reference. The range labeled ASHRAE 90E includes the simulation results for seven U.S. cities and two office building configurations [5]. The other range covers the California Title 24 Standards for offices [8]. Neither the ASHRAE nor the Title 24 range include realistic estimates of energy used by miscellaneous process loads such as exterior lighting, but buildings in BECA-CN do. (Since we are not sure how significant these exclusions are, we are currently studying this issue in greater detail.) We have also plotted the average existing office buildings for the Northwest [1].

Energy Intensity vs. Building Size. We have examined the relationship between energy intensity and floor area for a number of BECA-CN samples. Figure 6 for the Northwest shows the same pattern that exists for the national BECA-CN data base. That is, there is a greater spread in energy intensities among smaller buildings than larger ones. This is possibly a surface area to volume effect: climate variations appear to have a greater impact on smaller buildings where the surface to volume ratio is higher. The retail building with about $400 \mathrm{kft}^{2}$ appears not 


\section{SUMMER VS WINTER PEAK POWER}

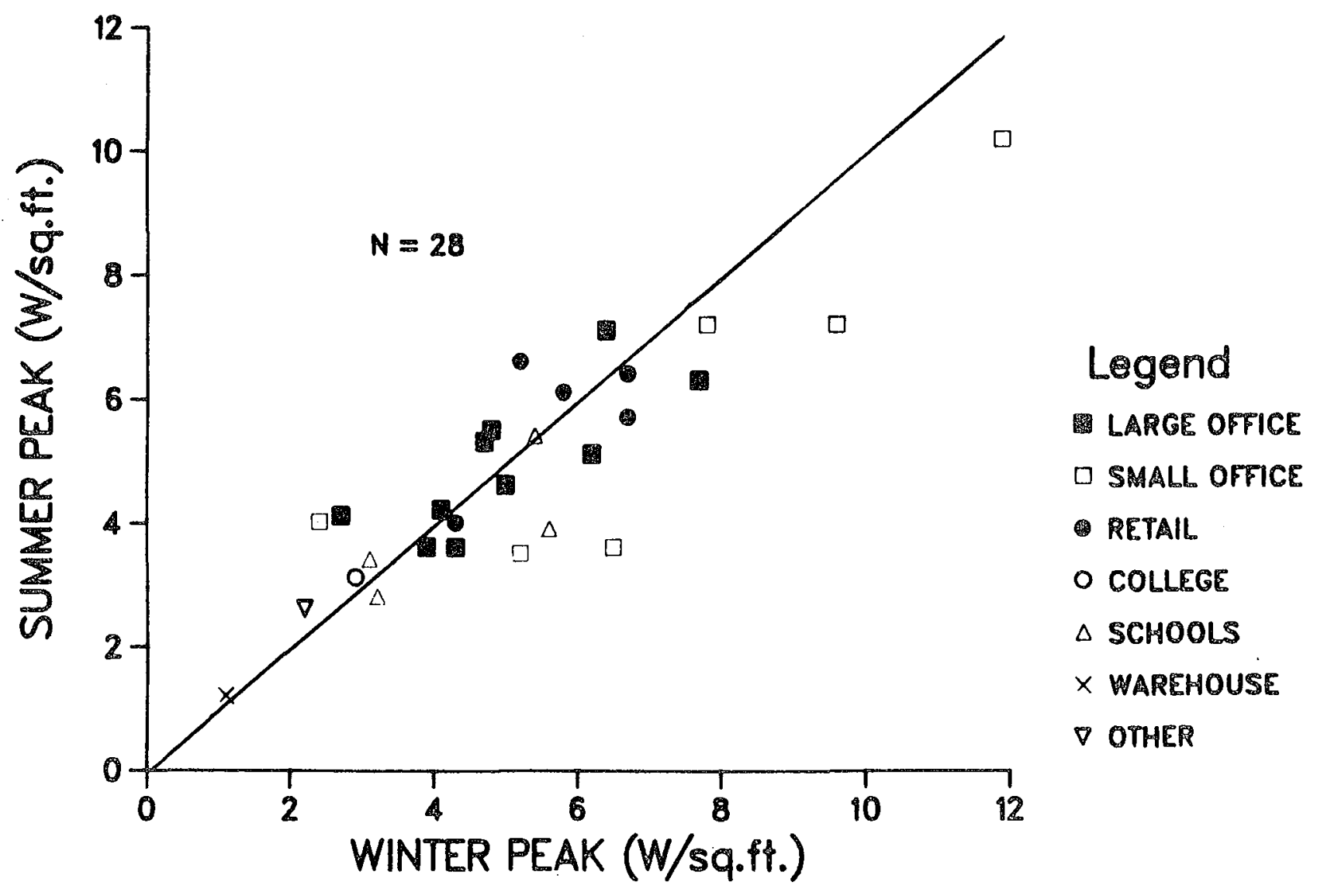

$X B L \quad 857-3127$

Figure 4. Winter versus summer electric peak demand. For the 28 buildings with available data, 15 peaked in the winter, 12 in the summer, and one had equal peaks. 


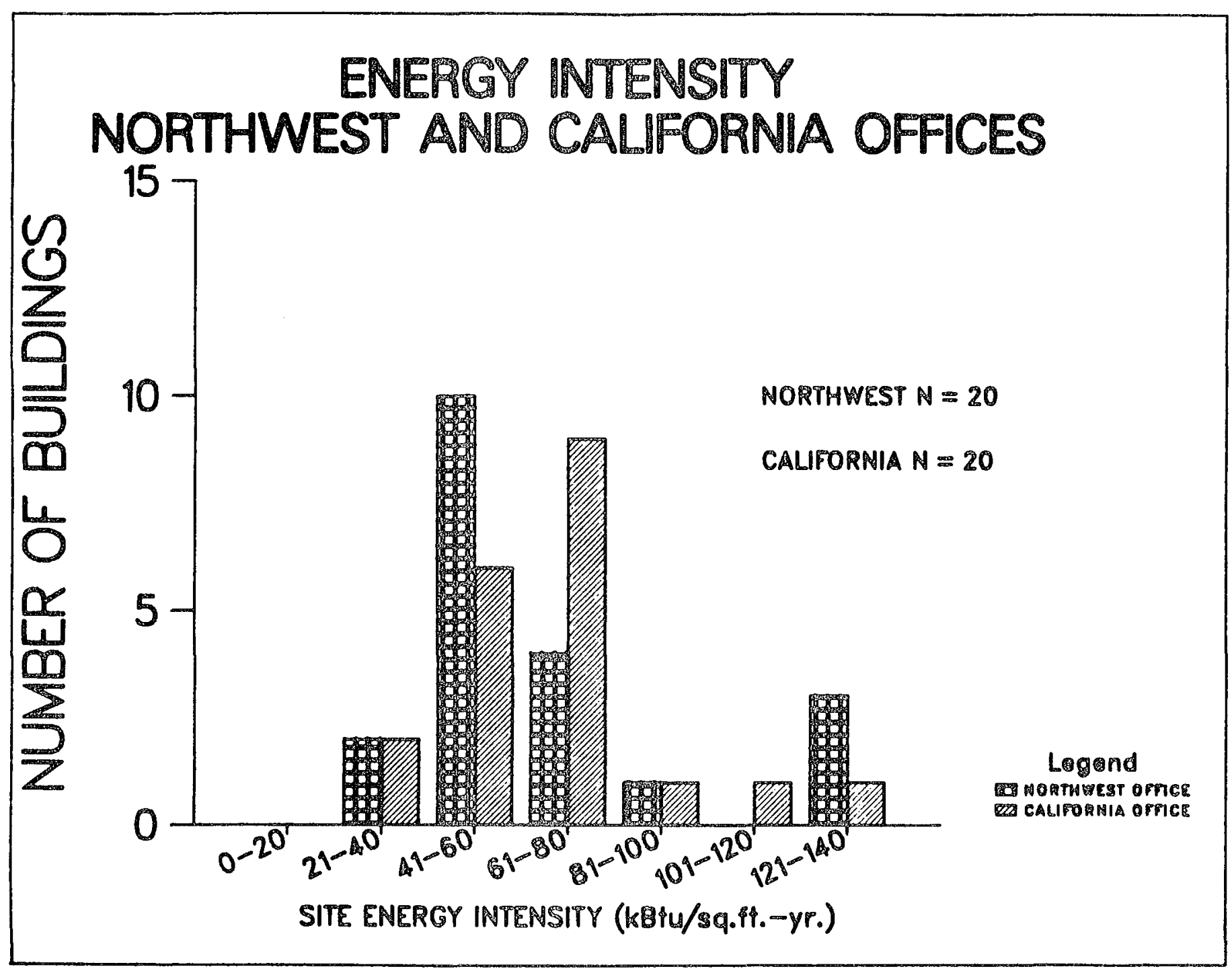

XBL $857-3130$

Figure 5. Distribution of energy intensities for Northwest versus California offices. For equal samples of California and Northwest offices, the Northwest were lower energy users. Also included are reference numbers: 1) proposed ASHRAE standard $90 \mathrm{E}$ has a range of 39-57 kBtu/ $\mathrm{ft}^{2}-\mathrm{yr}_{\mathrm{r}}$, 2) California current Title 24 standards for offices range from 43 to $54 \mathrm{kBtu} / \mathrm{ft}^{2}-\mathrm{yr}$, and 3) Northwest average office stock is estimated to be $123 \mathrm{kBtu} / \mathrm{ft}^{2}-\mathrm{yr}$. 


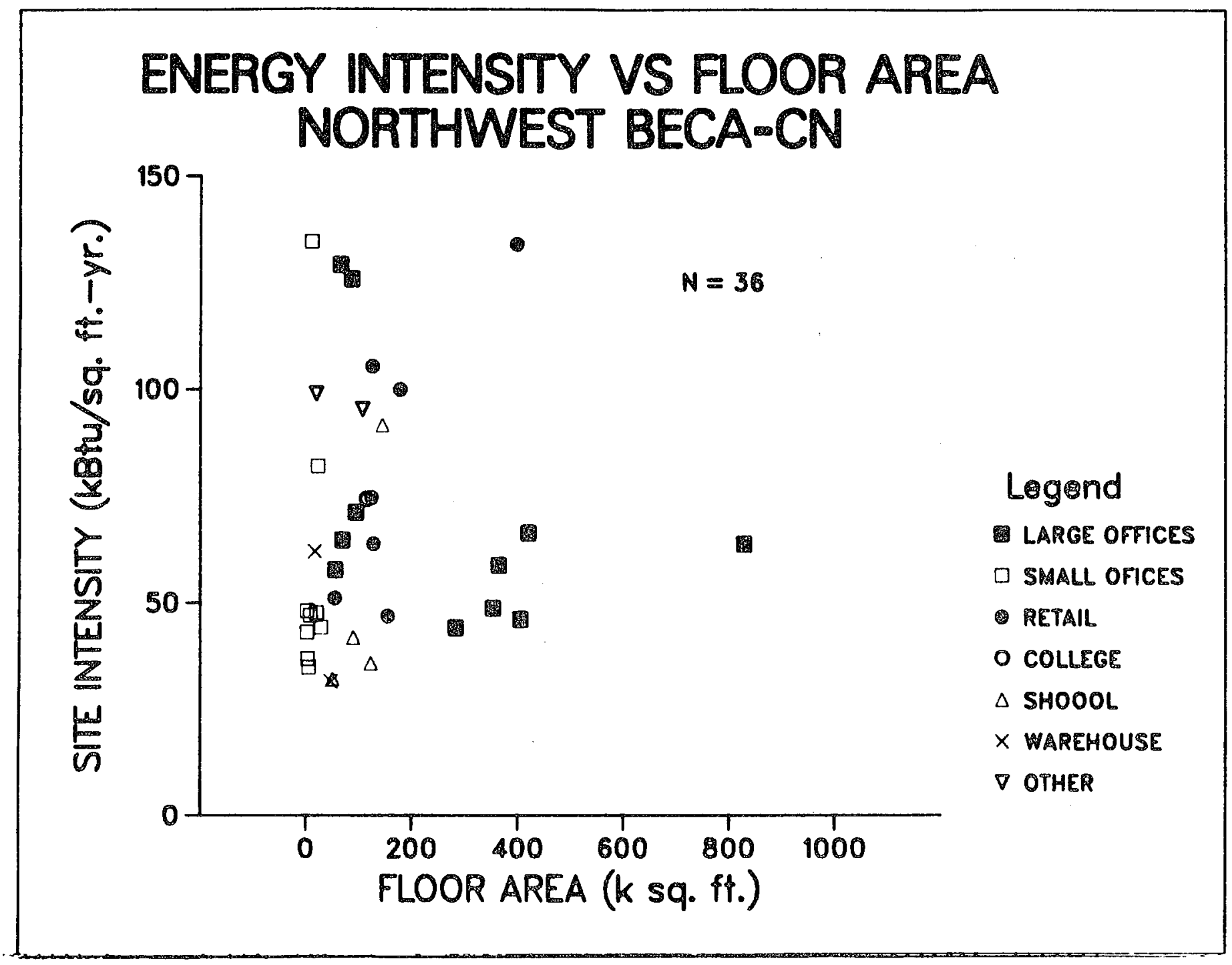

XBL $857-3129$

Figure 6. Energy intensity versus total gross floor area for Northwest BECA-CN. Larger buildings tend to have a smaller range in energy intensity than small buildings. We have seen the same result with the national BECA-CN sample of 133 buildings as well. 
to follow the trend for the other large buildings and may support this theory: it is the two-story shopping mall which has a larger surface area to volume ratio than large offices. An issue that complicates plotting floor areas is that the reported area of large buildings often includes partially conditioned spaces like enclosed parking. Small buildings are less likely to have significant fractions of their total enclosed space devoted to partially or nonconditioned areas.

\subsection{Limitations}

Evaluating a building in terms of its annual energy intensity has important drawbacks. Floor area discrepancies, variable operating conditions, process load variations, and other such complications are not reflected in annual energy intensities. For example many buildings in our sample have been included because their design features suggest they will be efficient; but they are, in fact, high-energy buildings. In some cases we have information about operating conditions that help explain high energy intensity; in many other cases we do not. We have already mentioned the example of the low-energy small office compared to the banks. We examine another example below.

Retail Example. Figure 7 shows 1983 energy costs per square foot for 171 shops, restaurants, and other tenants within a shopping mall. Almost every tenant has a separate meter. The sites with high annual energy costs are probably small, fast food restaurants. Assuming an energy cost of 4 cents $/ \mathrm{kWh}$, the most well represented group of $\$ 0.75 / \mathrm{ft}^{2}$-yr to $\$ 0.99 / \mathrm{ft}^{2}$-yr operate at about $22 \mathrm{kWh} / \mathrm{ft}^{2}-\mathrm{yr}$. This is below the estimate of the new average all-electric stock figure for retail $\left(30 \mathrm{kWh} / \mathrm{ft}^{2}-\mathrm{yr}\right)$, and a slightly above the estimated value for new buildings built to the regional standard $\left(18 \mathrm{kWh} / \mathrm{ft}^{2}-\mathrm{yr}\right)$. In any event, a very wide range of energy intensities is possible for sites within a single mall.

Evaluating the efficiency of this shopping complex in terms of total mall energy per square foot is complicated by the many different uses inside the building. For example, should the indoor ice-rink energy consumption be included in the total mall energy intensity value, or not? Certainly the cooling provided from the ice-rink reduces the cooling requirements inside the mall, but it is not a standard load for retail buildings. It has been included because it is not separately metered and we are unable to separate it out.

\section{CONCLUSIONS}

We have collected measured data that support the case for feasible low-energy buildings. Most of the buildings we examined are operating well below stock averages, and about half operate below the estimated energy intensities for new construction under the MCS. We have talked to many satisfied building owners and managers with low energy bills and no major

The data do not include the energy usage of the five major department stores within the mall. Separate data were collected for two of these five, and are included with the thirty-six BECA-CN buildings. 


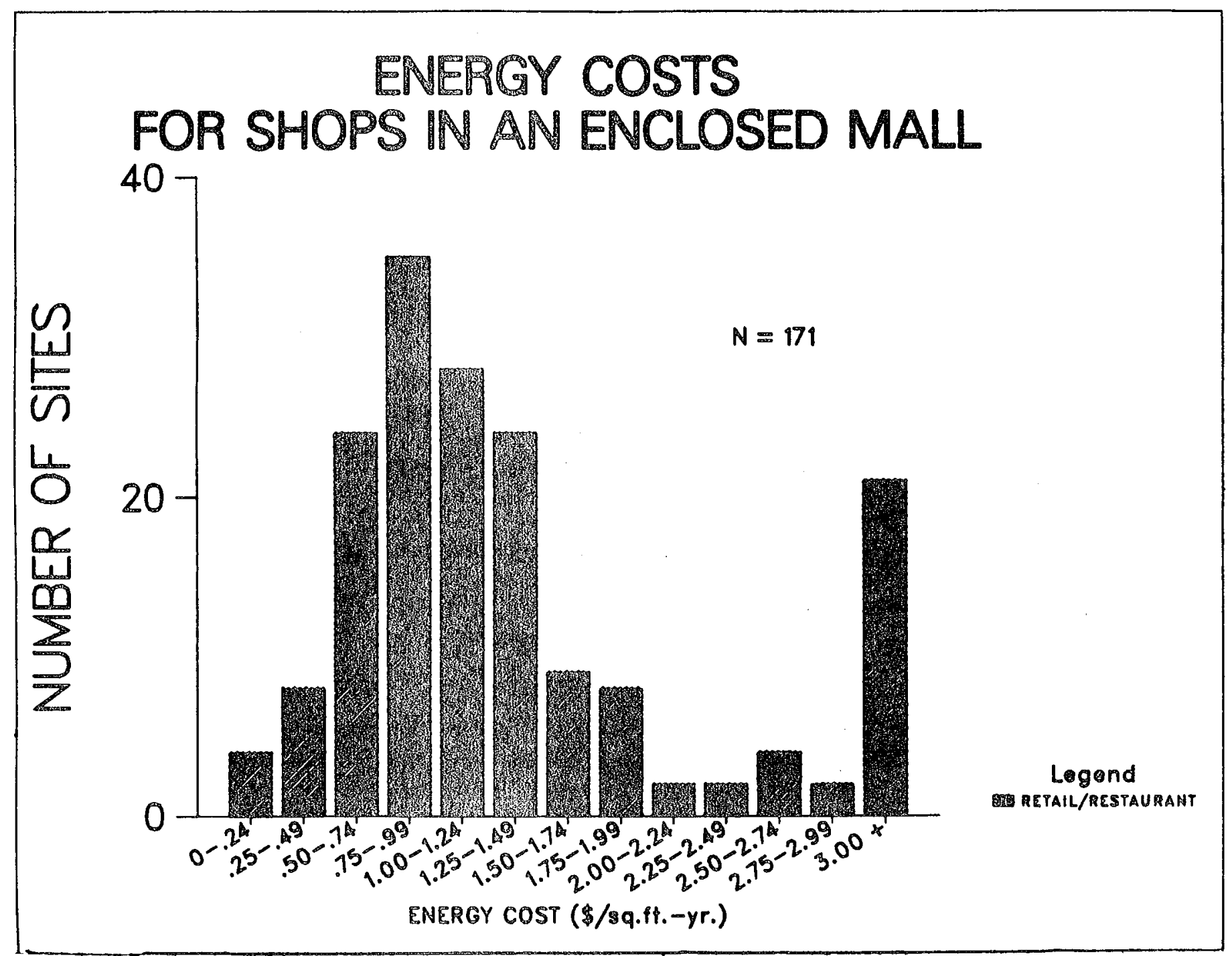

XBL $857-3128$

Figure 7. Annual energy costs for shops in an enclosed mall. The clear middle peak shows most of the buildings operate within a small cost range, and have similar energy consumption patterns. At an energy cost of $\$ 0.04 / \mathrm{kWh}$ the majority are operating at about $22 \mathrm{kWh} / \mathrm{ft}^{2}$-yr, below average new stock, but above the regional standard estimates. The large bin for buildings operating at over $\$ 3.00 / \mathrm{ft}^{2}$-yr is probably from small, energy-intensive restaurants. 
problems with innovative energy features. In addition, the economic data suggest it is possible to build an energy-efficient building for no more than average construction costs.

Many of the buildings, however, are not performing as well as expected. For all six of the buildings for which we have both actual and predicted data, recent energy use is above the designed performance. These discrepancies are to be expected because the "predictions" may, for example, have been generated using different operating hours, weather conditions, or office equipment loads than the actual building. To understand the data we have looked at the relationships between energy intensity and operating hours, lighting levels, floor area, year built, and HVAC equipment types. We have not seen much correlation. We have tried to identify energy intensities and characteristics of "efficient" buildings for a variety of building types, and evaluate the limitations of assessing the whole-building energy data. We have shown that it is very difficult to classify many commercial buildings into standardized types because they serve multiple functions.

To further substantiate these conclusions, end-use data are necessary. Over the next year, we will begin to analyze submetered data from PNL's End-Use Load Conservation and Assessment Program (ELCAP). Other areas of future research include analyzing the monthly energy consumption collected for all but three of the buildings in this sample. We are hoping to develop normalization procedures to account for effects of weather, occupancy, and other operating variables. We also plan to examine the multi-year data, available for half of the buildings, for performance trends.

\section{ACKNOWLEDGMENTS}

The authors would like to graciously thank the many people who supplied the actual building data for this study, as well as those who provided us with valuable leads to new data. We also thank the BPA and Northwest Regional Power Planning Council staff for their assistance. Finally, we thank John Hartmann for his help with data collection.

The work described in this paper was funded by the Bonneville Power Administration and

the Assistant Secretary for Conservation and Renewable Energy, Office of Building Energy Research and Development, Building Systems Division of the U.S. Department of Energy under Contract No. DE-AC03-76SF00098.

\section{REFERENCES}

1. Northwest Power Planning Council, Regional Conservation and Electric Power Plan, Table K.24, Portland, Oregon, January 1983.

2. Northwest Power Planning Council, Model Conservation Standards Equivalent Code, Portland, Oregon, February 1985.

3. Shopping Center World, "Retail Expansion Plans Show Renewed Faith in Industry's Future" Atlanta, Georgia, December 1983, p. 36. 
4. L. Wall, M. Piette, and J. Harris A Summary Report of BECA-CN: Buildings Energy-Use Compilation and Analysis of Energy Efficient New Commercial Buildings, Buildings Energy Data Group, Lawrence Berkeley Laboratory, Berkeley CA, July 1984.

5. Battelle Pacific Northwest Laboratory (PNL), Recommendations for Energy Conservation Standards and Guidelines for New Commercial Buildings, Volume III: Description of the Testing Process, Report \# DOE/NBB-0051, October 1983.

6. McGraw-Hill Information Systems Company, Dodge Construction Systems Costs 1982, New York NY, 1981.

7. McGraw-Hill Information Systems Company, Manufacturing/ Office/ Warehouse Building Costs, New York NY, 1976.

8. California Energy Commission, Energy Conservation Manual: Design for Compliance, The 1985 Office Building Energy Conservation Standards, September 1984. 
POSTSCRIPT (March 1985)

We have collected additional data since we completed our analysis in 1984. In general, these new data further support our conclusions. Data tables are included for five additional buildings at the bottom of the data tables in Appendix $\mathrm{A}$.

New buildings. Predicted energy intensity was available for three of these buildings. One is performing remarkably close to predicted intensity; the other two are using about twice as much energy as predicted. It is not clear from the data we've gathered why the one building is operating so close to its predicted energy intensity. One possibility is that its predicted value, 73 $\mathrm{kBtu} / \mathrm{ft}^{2}-\mathrm{yr}$, may be more reasonably correlated to the actual operating conditions of the building, as built, than were the other two values. But, as noted in the data tables, the gross floor area may not be the same as the area used by the engineers to predict energy intensity. It is worth noting that the energy intensities of the other two buildings are expected to come down over the next year.

The building using $20.5 \mathrm{kBtu} / \mathrm{ft}^{2}-\mathrm{yr}$, which appears especially efficient, is a passive solar church with minimal use. Both of the new small offices are operating at intensities far above the maximum intensity of any of the small offices included in the original thirty-six buildings. One of these was a well-publicized, award winning building, operating longer hours than assumed in the designed energy intensity. In addition, computer loads complicate the performance data for these buildings.

Future work. BPA is funding a number of other projects related to BECA-CN. One study currently in progress will focus on about a dozen case studies of notably energy-efficient, successful commercial buildings. Some of these buildings are presently contained in BECA-CN. BECACN will incorporate new data from these case studies, along with about thirty new, Seattle ELCAP buildings over the next year. These additional data will provide new insights into the issues discussed in this paper. 


\section{APPENDIX A}

DATA TABLE 1: CHARACTERISTICS OE BUILDINGS IN THE NORTHWEST

$\begin{array}{cllllllllllllllllllllll}N=36, & \mathrm{DEC} \cdot 1984 \\ (\mathrm{~A}) & \text { (B1) } & \text { (B2) } & \text { (C) } & \text { (D) } & \text { (E) } & \text { (E) } & \text { (G1) } & \text { (G2) } & \text { (G3) } & \text { (H) } & \text { (I1) } & \text { (I2) } & \text { (J1) } & \text { (J2) } & \text { (K1) } & \text { (K2) } & \text { (I) } & \text { (M) }\end{array}$

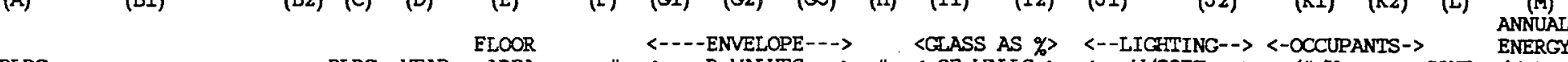

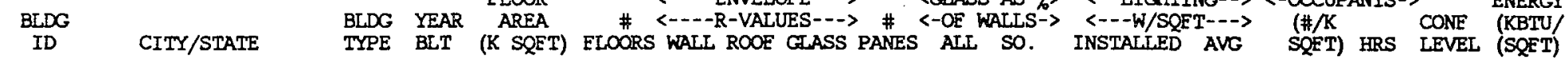

\begin{tabular}{|c|c|c|c|c|c|c|c|c|c|c|c|c|c|c|c|c|c|}
\hline 1 & SEATTLE & WA LOEE & 1973 & 830.0 & 38 & & & & & $50 \%$ & & & 3.5 & 3.0 & $\mathbf{R}$ & $B$ & 63.4 \\
\hline 165 & PORTIAND & OR LOFE & $\begin{array}{l}1975 \\
1982\end{array}$ & $\begin{array}{l}420.5 \\
406.0\end{array}$ & 15 & & & & 1 & & & & & 3.2 & $\mathbf{R}$ & $\begin{array}{l}\mathrm{B} \\
\mathrm{B}\end{array}$ & $\begin{array}{l}66.0 \\
45.8\end{array}$ \\
\hline 169 & PORTLAND & OR LOEE & 1980 & $365.0 \mathrm{C}$ & & & & & 2 & & & & & 3.3 & $\mathbf{R}$ & B & 58.5 \\
\hline 56 & TACOMA & WA LOEE & 1971 & $354.1 \mathrm{C}$ & 5 & 11.1 & 11.1 & & & & & 2.8 & & 2.5 & $\mathbf{R}$ & B & 48.4 \\
\hline 70 & IDAHO EALLS & ID LOFE & 1979 & 284.0 & 3 & 12.5 & 16.7 & & 2 & $40 \%$ & $40 \%$ & 1.4 & 1.2 & 5.3 & $\mathbf{R}$ & & 43.8 \\
\hline 171 & SEATTLE & WA LOFE & 1981 & 95.5 & 2 & 16.7 & 16.7 & & 2 & & $50 \%$ & 3.0 & & 4.5 & $\vec{E}$ & B & 70.9 \\
\hline 158 & CORVALLIS & OR LOEF & 1983 & 89.0 & 2 & 11.0 & 18.9 & & 2 & & & & & 4.8 & $\overline{\mathbf{R}}$ & $\mathrm{B}$ & 125.7 \\
\hline 157 & SEATTLE & WA LOEF & 1982 & 70.0 & 5 & & & & 2 & & & 1.8 & & 3.7 & $\mathrm{E}$ & B & 64.4 \\
\hline 162 & PORTLAND & OR LOEF & 1978 & 68.0 & 4 & 7.7 & 10.9 & 1.9 & 2 & $22 \%$ & $13 \%$ & & 3.0 & 3.7 & & $\bar{A}$ & 129.0 \\
\hline 163 & BOZEMAN & MT LOFE & 1979 & 56.7 & 3 & 8.3 & 25.0 & 2.0 & 2 & $47 \%$ & $52 \%$ & & 3.0 & 3.5 & $\mathrm{~F}$ & B & 57.4 \\
\hline 174 & NEWPORT & OR SOEE & 1982 & 29.6 & 2 & & & & & & $90 \%$ & 1.7 & & 3.4 & $\mathrm{R}$ & B & 44.0 \\
\hline 82 & RICHLAND & WA BANK & 1980 & 24.7 & & & & & & & & & & & $\vec{E}$ & $\vec{C}$ & 81.8 \\
\hline 78 & COEUR D'ALENE & ID SOEE & 1981 & 21.5 & 2 & 20.0 & 30.3 & & 2 & & & & & 3.3 & $\bar{R}$ & B & 47.4 \\
\hline 68 & SPOKANE & WA BANK & 1979 & 13.5 & & 8.3 & 14.3 & & & & & & & 3.7 & $\mathbf{R}$ & B & 134.5 \\
\hline 161 & SUNNYSIDE & WA SOEE & 1981 & 9.7 & 1 & 14.3 & 25.0 & 1.8 & 2 & & & & & 6.2 & $\mathbf{R}$ & B & 46.8 \\
\hline 175 & SWEET HOME & OR SOFE & 1979 & 6.3 & 3 & & & & 2 & $6 \%$ & $6 \%$ & & & & $\mathbf{R}$ & B & 34.7 \\
\hline 166 & YAKIMA & WA SOEE & 1982 & 4.5 & 1 & 22.7 & 33.3 & & 2 & & $13 \approx$ & 2.4 & & 6.7 & $\vec{E}$ & $B$ & 36.7 \\
\hline 150 & BOISE & ID SOEF & 1978 & 3.2 & $\overline{2}$ & 18.9 & 20.0 & & 2 & & $10 \%$ & & & 4.4 & $\vec{R}$ & B & 47.9 \\
\hline 177 & SPRINGE IELD & OR SOFE & 1977 & 3.1 & 2 & 20.0 & 40.0 & & 2 & & & & & & $\mathbf{R}$ & B & 42.9 \\
\hline 173 & PORTLAND & OR SHOP & 1981 & 400.0 & 2 & & & & & & & & & & $\vec{E}$ & $\mathrm{c}$ & 133.8 \\
\hline 155 & BELLEVUE & WA DEPT & 1982 & 180.0 & 3 & & & & & & & & & & & C & 99.7 \\
\hline 151 & PORTLAND & OR DEPT & 1981 & 155.9 & & & & & & & & & & & $\mathbf{E}$ & B & 46.7 \\
\hline 153 & PORTLAND & OR DEPT & 1981 & 128.9 & 2 & & & & & & & & & & & $\bar{c}$ & 63.6 \\
\hline 154 & TACOMA & WA DEPT & 1983 & 127.8 & 2 & & & & & & & & & & & $c$ & 105.1 \\
\hline 152 & LYNNWOOD & WA DEPT & 1979 & 125.1 & 2 & & & & & & & & & & & C & 74.4 \\
\hline 176 & EUGENE & OR DEPT & 1983 & 55.9 & 1 & & & & 2 & & $2 \%$ & & & & E & $\mathbf{B}$ & 50.9 \\
\hline 164 & TACOMA & WA COLL & 1980 & 115.9 & 7 & & & & & & & & & 7.1 & $\mathbf{E}$ & B & 74.1 \\
\hline 160 & SPOKANE & WA SECN & 1982 & 146.0 & 2 & & & & & $6 \%$ & & & & 9.0 & $\bar{R}$ & B & 91.4 \\
\hline 168 & PENDLETON & OR ELEM & 1982 & 123.7 & 2 & & & & & & & 2.1 & & 17.5 & $\mathbf{R}$ & B & 35.6 \\
\hline 159 & PUYALLUP & WA ELEM & 1981 & $90.2 \mathrm{C}$ & & & & & 3 & & & & & & $\vec{R}$ & $\mathrm{C}$ & 41.6 \\
\hline 156 & BOISE & ID ELEM & 1979 & 51.4 & 1 & 16.7 & 25.0 & & & $6 \%$ & $6 \%$ & & & & & A & 31.9 \\
\hline 170 & BILLINGS & MI WARE & 1978 & 48.0 & 1 & & & & & & & & & & $E$ & C & 31.5 \\
\hline 167 & LEWISTON & MT WARE & 1981 & 18.0 & & & & & & & & & & 1.7 & $\mathrm{R}$ & B & 61.9 \\
\hline 172 & SEATTLE & WA OTHR & 1983 & 108.4 & 2 & 16.7 & 16.7 & & 2 & $65 \%$ & $50 \%$ & 3.0 & & 1.8 & $\mathbf{R}$ & B & 95.2 \\
\hline 178 & SPOKANE & WA OTHR & 1980 & 21.2 & & 12.5 & 30.3 & & & & & & & 43.9 & E & A & 98.9 \\
\hline
\end{tabular}

$\mathrm{N}=5$, MARCH 1985

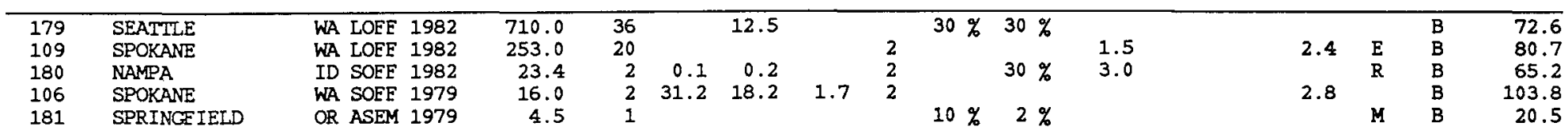


J2. AVERAGED USED LIGHTING LOAD (W/FT ${ }^{2}$ ): average used load. This data is also often estimated. May or may not include task lighting.

K1. OCCUPANTS NUMBER/KFT ${ }^{2}$ : average number of occupants per $1000 \mathrm{ft}^{2}$. This data is also often estimated.

K2. OCCUPANTS HOURS: building occupancy code; M- minimal (less than $40 \mathrm{hrs} /$ week); Rregular (40-50 hrs/week); E-extended (51-75 hrs/week); F-full (76-168 hrs/week).

L. BUILDING CONFDENCE LEVELS: Our assessment of the data quality. A - well documented case study information, high confidence in most values; B - reported or certified by reputable person who had direct access; C - marginally acceptable, second hand data.

M. ANNUAL ENERGY (KBTU/FT ${ }^{2}$-YEAR): Total site energy intensity. Electricity is multiplied by 3413 to convert $\mathrm{kWh}$ to Btu.

Data Table 2 Definitions

N1. LIGHTING TYPE 1: space for the three main types are recorded in the data base. The most predominant two are printed here. The first type is the major type. The codes are: FLU - fluorescent; HGV - mercury vapor; HAL - metal halide; INC - incandescent; HPS high pressure sodium; HID - high intensity discharge (when we don't know if it is HGV, HAL, or HPS).

N2. LIGHTING TYPE 2: see above (N1).

N3. DAYLIGHT TYPE: RF - reflectors for bouncing light into the building; LW - light wells; SKY - skylights for lighting (not included if just decorative); RM - roof monitors; AT atrium for lighting (often for solar gain as well as light); SH - light shelves;

N4. LIGHT CONTROLS: SW - switches for banking rooms or floors; CP - computerized (on the Energy Management System); PC - photocell for dimming with daylight sources; RS - radio active switches for easy control; DM - dimmers that allow selective reductions; OT - other type.

O1. SPECIAL EQUIPMENT:

ST Thermal Storage (water tanks for heat storage, eutectic salts, etc.) 
TM Thermal Mass (usually trombe walls, passive solar)

SO Active Solar

EB Earth Berms

EZ Economizer

HR Heat Recovery

HL Heat Recovery Luminaires

OP Operable Windows

FS Fixed Shading

OT Other

O2. SPECIAL CONTROLS OR CONTROL STRATEGIES:

EMS Energy Management Control System

NS Night Setback

NC Natural cooling/night ventilation

TM Timers/clock thermostats

P1: PRIMARY HEATING FUEL:

S Steam

E Electricity

G Natural Gas

$\mathrm{X}$ Other (one case include purchased geothermal hot water)

H Solar

P2: PRIMARY HEATING EQUIPMENT DESCRIPTION:

RS Resistance (electric)

HP Heat Pump

BO Boiler

IR Infrared (used in warehouses)

FR Furnace

RP Roof Top Package 
Q1: PRIMARY COOLING FUEL: All for this sample were - E (electric).

Q2: PRIMARY COOLING EQUIPMENT DESCRIPTION:

HP Heat Pump

$\mathrm{CH}$ Chiller (general type)

CC Centrifugal Chiller

AC Absorption Chiller

RP Rooftop Package

DR Direct Expansion Reciprocating Cooler

Data Table 3 Definitions

R1. YEAR OF DATA: most recent year of energy data available for the building. The year built (D) is printed next to this field to show the age of the building for the year of data. For many of the buildings, this is the first year of operation.

R2. YEAR TYPE: the type of year for the operating data.

CY Calendar year

FF Federal Fiscal year (Oct. through Sep.)

SF State Fiscal year (July through June)

OT Other or Misc. year

9M Only 9 months of data was prorated for one building

S1. MEASURED ANNUAL ENERGY INTENSITY ELECTRICITY (KWH/FT ${ }^{2}$-YEAR): electrical energy consumption.

S2. MEASURED ANNUAL ENERGY INTENSITY FUEL, OTHER (KBTU/FT ${ }^{2}$-YEAR): fuel (gas, oil, etc.) and other (steam, chilled water, etc.) consumption totals at the site.

T. PREDICTED ANNUAL SITE TOTAL (KBTU/FT ${ }^{2}$-YEAR): predicted annual site energy intensity. Sometime these predictions do not include all of the building loads. When available we record the prediction method.

U1. MEASURED PEAK ELECTRICITY LOAD (W/FT ${ }^{2}$ ) WINTER: peak electrical load for the winter (heating) months of November through April. 
U2. MEASURED PEAK ELECTRICITY LOAD (KW/FT $\left.{ }^{2}\right)$ SUMMER: peak electrical load for the summer (cooling) months of May through October.

V. ANNUAL ENERGY COST $\left(1984 \$ / \mathrm{FT}^{2}\right)^{2}$ : total energy cost per $\mathrm{ft}^{2}$ for the recorded year of operation. All costs have been adjusted to first quarter 1984 dollars using GNP deflators from the first quarter dollars of the year for the energy data.

W. CONSTRUCTION COST $\left(1984 \$ / \mathrm{FT}^{2}\right)$ : total building construction cost per $\mathrm{ft}^{2}$ excluding land. Costs have been adjusted to first quarter 1984 dollars using GNP deflators.

X. CFA RATIO: conditioned floor area ratio. Obtained by dividing the conditioned floor area by the gross floor area.

Y. COMMENTS: miscellaneous information. 
